Abstracta Iranica Abstracta Iranica

Revue bibliographique pour le domaine irano-aryen

Volume 28 | 2007

Comptes rendus des publications de 2005

Foucault and the Iranian Revolution. Gender and the

Seductions of Islamism. Chicago et Londres, The University of Chicago Press, 2005, 346 p.

Azadeh Kian-Thiébaut

(2) OpenEdition

Journals

Édition électronique

URL : http://journals.openedition.org/abstractairanica/20191

DOI : 10.4000/abstractairanica.20191

ISSN : 1961-960X

Éditeur :

CNRS (UMR 7528 Mondes iraniens et indiens), Éditions de l'IFRI

Édition imprimée

Date de publication : 15 mai 2007

ISSN : 0240-8910

Référence électronique

Azadeh Kian-Thiébaut, "Foucault and the Iranian Revolution. Gender and the Seductions of Islamism.

Chicago et Londres, The University of Chicago Press, 2005, 346 p. », Abstracta Iranica [En ligne],

Volume 28 | 2007, document 391, mis en ligne le 18 septembre 2007, consulté le 25 septembre 2020.

URL : http://journals.openedition.org/abstractairanica/20191 ; DOI : https://doi.org/10.4000/

abstractairanica. 20191

Ce document a été généré automatiquement le 25 septembre 2020

Tous droits réservés 


\title{
Foucault and the Iranian Revolution. Gender and the Seductions of Islamism. Chicago et Londres, The University of Chicago Press, 2005, 346 p.
}

\author{
Azadeh Kian-Thiébaut
}

Le renversement du régime du chah a été soutenu à travers le monde par des intellectuels progressistes qui restaient néanmoins sceptiques quant à la notion d'une république islamique. Michel Foucault est une exception à cette règle car il a soutenu, avec enthousiasme, la révolution iranienne qu'il considérait comme une nouvelle forme de spiritualité politique. Il a visité l'Iran deux fois en 1978, afin, disait-il, d'assister à la naissance des idées, et a rencontré l'Āyatollāh Homeynī en septembre de la même année pendant son exil en France. Cet ouvrage inédit analyse les raisons du soutien apporté par Foucault à la révolution iranienne et présente, pour la première fois en anglais ses écrits et ses interviews sur l'Iran. A travers une lecture critique de ces textes, les AA. cherchent les fondements théoriques des prises de position de Foucault et soulignent l'importance cruciale de l'épisode iranien pour ses écrits dans les années 1980. Selon les AA., le soutien de Foucault à la révolution iranienne s'explique, en partie, par son concept d'authenticité. Pour Foucault, la créativité trouve son origine dans des situations dangereuses où la population flirte avec la mort. L'ouvrage souligne aussi l'orientalisme romantique de Foucault et tente de démontrer qu'il privilégie les cultures anciennes et traditionnelles par rapport aux cultures modernes. Foucault était très intéressé par le déploiement de certains instruments de modernité comme moyens de résistance et a souligné les usages innovants des programmes audio-visuels faits par les islamistes, l'appropriation des mythes chi'ites de martyre par le mouvement révolutionnaire ou la volonté de beaucoup d'Iraniens d'aller à la rencontre de la mort pour renverser le régime du chah. Pour les AA., l'expérience iranienne a aussi montré que Foucault n'a pas pu anticiper la naissance d'un Etat moderne où les anciennes technologies religieuses de domination pouvaient être remodelées et institutionnalisées. Cet ouvrage montre aussi que les rapports très problématiques de 
Foucault avec le féminisme deviennent plus qu'une lacune dans le cas de l'Iran où il a très peu critiqué les doctrines islamistes des autorités religieuses sur les droits des femmes et où il est resté indifférent à l'égard des femmes iraniennes. Contrairement à ceux qui ont qualifié d'erreur l'affinité de Foucault avec les islamistes iraniens, les AA. estiment qu'elle révèle les ramifications de son discours nietzchéen-heideggerien. Pour les AA., la différence entre le grand récit de Foucault et ceux des libéraux ou des marxisants est que le récit de Foucault ne privilégie pas la modernité mais les ordres sociaux traditionnels.

INDEX

Thèmes : 12.1. Iran

\section{AUTEURS}

AZADEH KIAN-THIÉBAUT

Université Paris VIII / Mondes iranien et indien 